\title{
ASSESSING THE DISSIMILARITIES OF GAME MECHANICS ON ALBANIAN WORKING-CLASS CONSUMERS
}

\author{
Fortesa Haziri, Fortune Nwaiwu, Miloslava Chovancová
}

\begin{abstract}
The increase in popularity of games and their attendant impact on player behaviour has led to the transformation of game elements in line with non-game contexts. The process of adding game elements in non-game context has been defined as gamification. Due to digitization, consumers are exposed to a wider range of information through their use of technological devices and social media. Therefore, gamification is seen as innovative engaging and motivating set of activities that influence purchasing dispositions of consumers. Due to the successful usage of gamification in numerous areas, this study was aimed at exploring the game mechanics differences for employed consumers who purchase via social media (s-commerce). Using a survey as part of the research design, a questionnaire was employed for data collection, 183 respondents participated completed the questionnaire, and the data collected was used to perform the non-parametric test, Chi-Square test for independence has been employed to describe and explore the differences. The results revealed that points, rewards and badges offered by the s-commerce retailer as factors that influence the purchase frequency of consumers are significantly differ based on the working sector for employed consumers. The study provides substantial evidences for retail businesses regarding game mechanics elements as purchasing motivator.
\end{abstract}

Keywords: game mechanics, gamification, purchase, social media, user behavior, employees

\section{INTRODUCTION}

Purchasing via social media (s-commerce) has become an interesting research field. Moreover, to create a fun and enjoyable purchasing process game element may be employed. According to Gatautis et. (2016), the term of gamification was first used in sometime around 2002, but it was not until 2010 that the concept of gamification gained popularity and received greater interest, it attracted the attention of game creators who were interested in using gaming techniques in increasing players' engagement. Coincidentally, the concept has now received tremendous interest from stakeholders in the business world. Elements of e-games are often adapted and employed in real-life non-game environments as factors for engaging and motivating consumers. Gamification involves the adoption and incorporation elements associated with games as means of motivating, engaging and influencing the consumers' purchase and consumption behaviors, this is achieved by ensuring that the experience of the consumer becomes more pleasurable and exciting. The exploration of gamification is not restricted to the domain of consumer behavior. It has found successful applications in fields as diverse as education and training, marketing, social awareness, sales and human resources. (Calderón, Boubeta-Puig, \& Ruiz, 2018). Presently, the internet has enhanced the usage of technology. Also, the daily use of social media platforms such as Facebook, YouTube, Twitter, Instagram has been shown to have an impact on the communication process between the endusers and technology devices (Decker \& Trusov, 2010). According to Internet World Stats (2018), there are over 4 billion Internet users globally as at June 30, 2018.

Hsu and Chen (2018) argue that gamification has an effect on retention and customer loyalty; however, they stated that customers should first be engaged in playful experiences. Hence, 
embracing gamification can be a marketing and business strategy applied to increase customer engagement and loyalty. Purchasing transcends the basic need for a product or service. Purchasing motivation is also evoked by factors such as passable play, social collaboration, and economic reasoning. The stated reasons are valid and impact the amount of money spent on the in-game environment. Furthermore, the designers apply unreal limitations and obstacles along with the social collaboration impact the amount of money spent on the in-game environment (Hamari et al., 2017). Also, the in-game environment enables consumer engagement and it is potentially linked to the consumers' psychological engagement and behavioral engagement levels. The key pillars for psychological engagement are listed as game satisfaction, game customization and social collaboration (Cheung, Shen, Lee, \& Chan, 2015).

Models and elements of gamification have been studied by scholars; the studies differ according to various fields. For research purposes, the MDA framework has been considered as the most suitable for researching gamification in relations to issues such as consumer behavior. According to the MDA (acronym for game mechanics, dynamics, aesthetics) framework (J. T. Kim \& Lee, 2015; Werbach \& Hunter, 2012), gamification elements are game mechanics, game dynamics and aesthetics/emotions. The mentioned components were employed in the design of the questionnaire used for this study; the questionnaire was distributed to respondents in the Republic of Albania (hereinafter: Albania). Game mechanics are described as the rules, rewards, instruction and the limits for players to be followed. Those rules can be applied to online purchases as well.

Despite the high number of published guidelines and broad research, the gamification and game mechanics power for engaging and motivating consumers in developing countries has not been sufficiently explored which leaves a lot of gap within scientific literature. Due to lack of studies regarding game mechanics appliance, the study aims to fill this gap in theoretical and practical scope by assessing the dissimilarities of game mechanics on Albanian working class consumers. Furthermore, the research seeks to study the differences within working sector among Albanian citizens who use social media for purchasing purposes. By the same token, the authors did not find significant evidence to indicate that a study regarding the influence of game mechanics for social media purchasers has been investigated, notably within the context of developing countries.

\section{LITERATURE REVIEW}

The increasing popularity of social media platforms, such as Facebook, Instagram and Twitter are significantly influencing consumer purchasing behavior. It is now common for users of these platforms to share product information with those within their network. Also, these consumers are encouraged by social media features to articulate their affinity or dislike towards products and services. They may also "consult their social community to seek advice in their purchasing decisions" and through social communities' consumers have the potential to affect the buying decisions of much larger communities (Baethge, Klier, \& Klier, 2016; Shin, 2013). There are several factors proposed by researchers as catalysts of the growth of s-commerce especially among consumers in the working class sector of social demographics. Some of these factors include - rising trust levels attributable to the impact of micro-influencers; the preponderance of video and its impact on subtle, indirect influence of consumer choices; conversation through channels such as email and messenger apps are increasingly leading to an uptake of s-commerce; and social media interactions leads to an ever increasing level of impulse purchases online. There are numerous examples of successful use case of s-commerce such as Marvel studios selling movie tickets with Social Commerce and Nike's partnership with Snap through which it promoted the new Air Jordan III "Tinker", and after an NBA All-Star game, 
the shoes were sold out in a record 23 minutes (Baethge et al., 2016; S. Kim \& Park, 2013; Olbrich \& Holsing, 2011).

In the quest to apply the concept of gamification, there has been various models that have been proposed among different domains. Calderón, Boubeta-Puig and Ruiz (2018) adopted the Model-Driven Engineering (MDE) and Complex Event Processing (CEP) technology (MEdit4CEP-Gam) model to investigate the stages of origination, application and also monitor the applicable strategies of gamification. Gatautis et al. (2016) compared the SOR model against the pyramid of gamification proposed by Werbach and Hunter (2012). The authors found substantial uniformity between gamification elements and SOR model. However, no empirical research has been conducted that sheds light on evidence regarding similarities within the model. Rahman et al. (2018) established a framework by using gamification elements dynamics, behavior, component and aesthetic. This model canvas method was designed for cloud computing environment to persuade teachers on sharing the lessons of gamification. Kim and Lee (2015) used the attributes of game design, the features of learning games, the ARCS (attention, relevance, confidence, and satisfaction) and MDA framework to constitute the dynamical model for gamification of learning. The MDA framework is made up of a group of three elements, they are: game mechanics, game dynamics and aesthetics.

Part of MDA framework are game mechanics. Game mechanics has found extensive use within business education for generation Y. The results of the study highlight the differences between the groups where game mechanics were deployed and those that did not benefit from such deployment. Also, there was a noticeably better performance by students in the group where game mechanics were deployed, the level of collaboration and participation among students in this group was higher, there was also noticeable higher level of expression of positive emotional reactions, and willingness to share further opinions and comments concerning the class experience (Martin Poole, Kemp, Patterson, \& Williams, 2014). The class that did not use game mechanics recorded lower outcomes when compared to gamified classes. In the healthcare sector, game mechanics have resulted in improvements in patient engagement by creating challenging, entertaining, and improvements in how patients socialize (Hammedi, Leclerq, \& Van Riel, 2017). Nour, Rouf and Allman-Farinelli (2018) have studied the impact of game mechanics on engaging young adults (18-34 years old) on improving their consumption of vegetables. Overall, the study findings confirm that the application of mobile-gamified elements combined with the usage of social media has remarkable impact on improving the vegetable intake of this focus group. Regarding the specific elements which were found to be the most effective is the act or reward system of "earning badges". The study further highlights the importance of designing game elements by mentioning key features such as improved visual aesthetics, improvements in user experience (UX) via simplified design, credibility and relevance. Comparing two groups, one of the groups discussed the study environment and game mechanics were employed and the other group used a competitive discussion board game without game mechanics, whether the effect of presenting an activity as a game is relevant or not (Lieberoth, 2015). The sample study included students of age 20 to 43 years, and results indicated that vernacular and artifacts are psychologically powerful as game mechanics. For both groups, fun and enjoyment were significantly important, but motivation as a variable remained the same. In reference to age, a slightly negative correlation with relatedness was presented. The most important game mechanics to engage and motivate Taiwanese students of massive open online courses have been listed based on their level of importance as follows: virtual goods as gifts, redeemable points, team leaderboards, the Where's Wally game, trophies and badges (Chang \& Wei, 2016). The study concludes that Where's Wally game has occurred to be significantly important for engaging students of the massive open online courses. Significantly important according to results have been identified as game points, levels, avatars 
or virtual identity and badges (Scheiner, 2015). However, generally speaking, the participants of the study conducted by Scheiner (2015) ranked game mechanics as motivational factors for engaging consumers into idea competing provided by organizations.

The study by Hamari (2017) also confirms improvements in levels of engagement for participants when game mechanics are applied. The study was conducted over a two-year period, it utilized an experiment regarding the usage of badges in gamified utilitarian trading services as an incentive to influence user behavior. The results presented by the author corroborates other studies in regards to higher levels of significance for the end-users group after being introduced to gamification. The results from the study were in agreement with previous studies by researchers in the field (Hamari \& Koivisto, 2014; Hamari \& Tuunanen, 2014), where there was positive relationship between the features of the system and changes in user behaviors.

The impact of points, levels and leaderboards for an image annotation task, serve as external stimuli and it shows results for promoting level of performance only (Mekler, Brühlmann, Tuch, \& Opwis, 2017). A more elaborate study focused on leaderboards was conducted with focus on employee motivation and engagement. Leaderboards have been proven to be important for simple tasks and extraordinary efficient for hardly-achievable goals and tasks (Landers, Bauer, \& Callan, 2017). Furthermore, results from the study shows that points did not have an impact and on response accuracy. The successful appliance of game mechanics has been proven by numerous researchers as presented above. Concerning game mechanics impact on career awareness resulted significant due to the fact that game mechanics facilitated the communication with the system and provided additional options (McGuire, Broin, White, \& Deevy, 2018). However, no research was found in terms of comparison between working classes. Consequently, to explore and investigate the differences, the following hypothesis have been proposed:

H1: There is no association between the working sector and obtaining points, badges, and leader-boards when purchasing via s-commerce.

H2: There is no association between working sector and thrilling benefits obtained while purchasing via s-commerce.

H3: There is no association between working sector and forgetting unpleasant events when purchasing via s-commerce.

H4: There is no association between rewards, points and badges as motivators while purchasing via s-commerce and working sector.

H5: There is no association between perceiving shopping via s-commerce as fun and enjoyable process and working sector.

\section{METHODOLOGY}

This study was carried out in order to identify the working class differences for employed Albanian consumers who purchase via social media while game mechanics are considered. In order to fulfil the aim of the study, and provide information regarding game mechanics differences, a survey instrument has been chosen as part of the research design. Initially by considering deductive approach, articles related to game mechanics, purchasing via scommerce and working class has been collected from Scopus and Web of Science which lead to problem formulation. Afterwards, the research was design in accordance with the theoretical knowledge as disposal. The questionnaire was used for data collection. The questionnaire contained five statements related to game mechanics initially designed in English and before 
distributed for data collection in Albania, it was translated to the local Albanian language to ensure that respondents who do not speak English are also covered during the data gathering phase of the research. The five statements of game mechanics were previously used to investigate user behavior of Kosovar and the same statement without a changed have been part of this study (Haziri, Chovancová, \& Fetahu, 2019; Haziri \& Chovancova, 2018). To measure the level of agreement for the five statements, a five-point Likert scale (1 - Strongly disagree, 2 - Disagree, 3 - Neutral, 4 - Agree, 5 - Strongly agree) was employed as the measurement scale.

In order to examine the relationship between variables, chi-square has been employed. To analyses the data collected in Albania, the chi-square test is used. Chi-square is a nonparametric test which examines the association between categorical variables which are correlated in some population (Tabachnick \& Fidell, 2014). From chi-square tests, the chisquare test for independence was employed to accomplish the research aim. The conditions which are two categorical variables, the sample size, two or more categorical or groups for each variable and the independence of observations to apply chi-square have been fulfilled. Besides, to measure the effect size chi-square independence test, Cramer's V has been observed. To explain Cramer's V the instruction from SPSS tutorial (2018) has been followed, therefore, the numbers between 0 and 1 has been used to provide explanation regarding the strength of the relationship between variables. After filtering 183 valid respondents were selected for further analyses. The data have been analyzed using SPSS version 23.

Tab. 1 - The game mechanics statements. Source: Haziri et al. (2019); Haziri \& Chovancova (2018)

\begin{tabular}{|c|c|c|}
\hline Dimension & Item & Survey statement \\
\hline \multirow[t]{5}{*}{$\begin{array}{l}\text { Game } \\
\text { mechanics }\end{array}$} & GM01 & $\begin{array}{l}\text { By buying via social media, I am able to obtain points, badges, and } \\
\text { leader-boards }\end{array}$ \\
\hline & GM02 & The benefits received for buying via social media are thrilling \\
\hline & GM03 & $\begin{array}{l}\text { Purchasing via social media helps me forget unpleasant events and } \\
\text { makes me feel better than others }\end{array}$ \\
\hline & GI & felt motivated by the rewards, points and badges offered by sell \\
\hline & Gl & media make shopping a fun and enjoyable process \\
\hline
\end{tabular}

To perform the chi-square has been used game mechanics and the working class of respondents. After fulfilling the two initial criteria, which were to identify consumers who purchase via social media and are employed, the comparison of working sector differences when game elements are employed became the goal to conduct this research. Therefore, the authors aim to identify the game mechanics differences between Albanians consumers who purchase via social media and are employed.

\section{RESULTS AND DISCUSSION}

Albanian working sector is divided in three segments employees in public sector, nonagriculture private sector and agriculture private sector. Based on the reports provided by Institute of Statistics - Instat (2019) $14.97 \%$ of employed Albanian work in public sector and $85.02 \%$ work in private sector (non-agriculture and agriculture). In the survey conducted in Albania the majority of employed respondents (83.6\%) work in private sector and the rest $(16.4 \%)$ work in public sector. Therefore, the sample size is representative and corresponds with the data provided by the Institute of Statistics - Instat.

To perform the chi-square test has been gathering data in Albania from 183 respondents. The chi-square results for working sector are presented in Table 2.

Based on the literature review which lead to problem formulation, the hypotheses were designed considering the theoretical knowledge as disposal. The empirical test of hypotheses are 
presented below which are expected to provide empirical evidences to support the hypotheses and fulfil the research aim.

Tab. 2 - Chi-Square test results $(n=183$, public sector $=30$, private sector $=153)$. Source: own research

\begin{tabular}{|c|c|c|c|c|c|c|c|c|}
\hline \multirow[t]{2}{*}{ Items } & \multirow[t]{2}{*}{ Level of agreement } & \multicolumn{2}{|c|}{ Public Sector } & \multicolumn{2}{|c|}{ Private sector } & \multicolumn{2}{|c|}{ Chi-Square } & \multirow{2}{*}{$\begin{array}{c}\text { Cramer's V } \\
\text { Value }\end{array}$} \\
\hline & & $\mathrm{n}$ & $\%$ & $\mathrm{n}$ & $\%$ & $\chi^{2}(4)$ & p-value & \\
\hline \multirow[t]{5}{*}{ GM01 } & Strongly disagree & 16 & 8.7 & 45 & 24.6 & \multirow[t]{5}{*}{8.477} & \multirow[t]{5}{*}{0.07} & \multirow[t]{5}{*}{0.215} \\
\hline & Disagree & 3 & 1.6 & 42 & 23 & & & \\
\hline & Neutral & 6 & 3.3 & 45 & 24.6 & & & \\
\hline & Agree & 1 & 2.2 & 18 & 9.3 & & & \\
\hline & Strongly Agree & 1 & 0.5 & 3 & 1.6 & & & \\
\hline \multirow[t]{5}{*}{ GM02 } & Strongly disagree & 6 & 3.3 & 16 & 8.7 & \multirow[t]{5}{*}{4.844} & \multirow[t]{5}{*}{0.30} & \multirow[t]{5}{*}{0.163} \\
\hline & Disagree & 7 & 3.8 & 35 & 19.1 & & & \\
\hline & Neutral & 7 & 3.8 & 44 & 24 & & & \\
\hline & Agree & 10 & 5.5 & 45 & 24.6 & & & \\
\hline & Strongly Agree & - & - & 13 & 7.1 & & & \\
\hline \multirow[t]{5}{*}{ GM03 } & Strongly disagree & 12 & 6.6 & 44 & 24 & \multirow[t]{5}{*}{6.039} & \multirow[t]{5}{*}{0.19} & \multirow[t]{5}{*}{0.182} \\
\hline & Disagree & 8 & 4.4 & 45 & 24.6 & & & \\
\hline & Neutral & 2 & 1.1 & 36 & 19.7 & & & \\
\hline & Agree & 5 & 2.7 & 21 & 11.5 & & & \\
\hline & Strongly Agree & 3 & 1.6 & 7 & 3.8 & & & \\
\hline \multirow[t]{5}{*}{ GM04 } & Strongly disagree & 15 & 8.3 & 45 & 24.6 & \multirow[t]{5}{*}{12.135} & \multirow[t]{5}{*}{0.01} & \multirow[t]{5}{*}{0.256} \\
\hline & Disagree & 3 & 1.6 & 46 & 25.1 & & & \\
\hline & Neutral & 3 & 1.6 & 35 & 19.1 & & & \\
\hline & Agree & 6 & 3.3 & 22 & 12 & & & \\
\hline & Strongly Agree & 3 & 1.6 & 5 & 2.7 & & & \\
\hline \multirow[t]{5}{*}{ GM05 } & Strongly disagree & 7 & 3.8 & 21 & 11.5 & \multirow[t]{5}{*}{3.858} & \multirow[t]{5}{*}{0.42} & \multirow[t]{5}{*}{0.145} \\
\hline & Disagree & 2 & 1.1 & 22 & 12 & & & \\
\hline & Neutral & 8 & 4.4 & 51 & 27.9 & & & \\
\hline & Agree & 8 & 4.4 & 43 & 23.5 & & & \\
\hline & Strongly Agree & 5 & 2.7 & 16 & 8.7 & & & \\
\hline
\end{tabular}

The chi-square test for independence indicated that no significant association between working sector and obtaining points, badges, and leader-boards $\chi^{2}(4, \mathrm{n}=183), \mathrm{p}=0.07$. Cramer's V resulted 0.215 , signifying that the association strength between variables is medium. Regarding the association between the thrilling benefits of purchasing via social media and working sector, the results of the chi-square independence test failed to identify an association $\chi^{2}(4, n=183)$, $\mathrm{p}=0.30$. Cramer's V resulted with 0.163 signifying that the association strength between working sector and the thrilling benefits of purchasing via social media is small to medium. For purchasing via social media and forgetting unpleasant events and working sector differences, no association was identified $\chi^{2}(4, \mathrm{n}=183), \mathrm{p}=0.19$. Regarding Cramer's V, which resulted 0.183 , the strength of the association is small to medium. Furthermore, the association between working sector and motivation elements such as rewards, points and badges offered by scommerce retailers' resulted significantly different $\chi^{2}(4, \mathrm{n}=183), \mathrm{p}=0.01$. Also, Cramer's V resulted 0.256 indicates a small to medium association. Indicating that the motivations to purchase via s-commerce differ for Albanian consumers based on the working sector. No significant association was identified between working sector and consumers who consider shopping via social media as fun and enjoyable process $\chi^{2}(4, n=183), p=0.42$. Cramer's V resulted 0.145 signifying that the association is small to medium.

After analyzing the results of chi-square, the hypotheses $\mathrm{H} 1, \mathrm{H} 2, \mathrm{H} 3$ and $\mathrm{H} 5$ are supported due to the fact that the no association have been identified between working sector and obtainability of game mechanics when purchasing via s-commerce. On the other hand, H4 is not supported due to the fact that the association resulted significantly different between rewards, points and badges as motivators while purchasing via s-commerce and working sector. The authors aimed 
to identify the differences between employed Albanian consumers who purchase via scommerce when game mechanics are considered, however, differences have been identified between working sector and game mechanics motivators such as rewards, points and badges. Indicating that s-commerce retailers are advice to pay close attention regarding game mechanics motivation elements based on consumers working sector.

\section{CONCLUSION}

The results of the current study depict the differences between game mechanics and Albania's working class consumers. Furthermore, the differences have been identified between game mechanics elements', rewards, points and badges, as motivators and working sector. Due to the fact that, the sample size corresponds with the reports presented by Institute of Statistics - Instat the results could be generalize for Albania citizens. For the rest of game mechanics elements, no association have been noticed. Therefore, regarding the benefits received for buying via social media are thrilling, forgetting unpleasant events by shopping via social media, and shopping via social media is fun and enjoyable process no differences were identified for game mechanics appliance despite working sector. Furthermore, the economy is highly depended in import goods, and it takes place in the group of the low-income country, namely consumers will be motivated by obtaining rewards, points and badges regardless working sector.

The aim of the research was to explore the differences between employed Albanian consumers when game mechanics are considered in a gamified purchasing setting. Furthermore, this study contribution is threefold. Initially, it provides information regarding game mechanics appliance in s-commerce consumer behavior as purchasing motivator. It also demonstrates the high importance of game mechanics successful design. Lastly, by empirically examining the employed consumers' differences for game mechanics elements, it provides significant contribution to science by extending the literature. Therefore, the current research creates a value-added on game mechanics, gamification and consumer behavior literature.

The findings of this research are beneficial for s-commerce retails business, mostly with the main purpose to attract and motivate consumers for purchasing behavior. The results are considerably useful to s-commerce retails trying to sell their products/services via s-commerce platforms. Also, for businesses who provide specified and/or general products/services for targeted employed consumers.

Similar to other research, the current study has its limitations. Although the results may be generalizing for countries that share same values, economic status as Albania, the study is limited to one country. The study sample is biased due to the fact that it provides information only for consumers who purchase via s-commerce, it would be interesting to compare the results for consumers who purchase offline and via m-commerce. Moreover, a comparison with unemployed consumers create an added value for retail businesses. Considering gamification as a broad concept additional game element may be investigated and provide important evidence for practitioners and researchers. Also, additional study can be conducted by adding extra variables such as education, gender and incomes.

\section{Acknowledgement}

The authors are thankful for the financial support provided by the Internal Grant Agency of Tomas Bata University in Zlín, No. IGA/FaME/2018/005. 


\section{References}

Baethge, C., Klier, J., \& Klier, M. (2016). Social commerce: state-of-the-art and future research directions. Electronic Markets, 26(3), 269-290. doi: 10.1007/s12525-016-0225-2

Berg, R. G. van den. (2018). Chi-Square Independence Test. Retrieved from https://www.spsstutorials.com/chi-square-independence-test/\#what-is-it

Calderón, A., Boubeta-Puig, J., \& Ruiz, M. (2018). MEdit4CEP-Gam: A model-driven approach for user-friendly gamification design, monitoring and code generation in CEPbased systems. Information and Software Technology, 95, 238-264. doi: 10.1016/J.INFSOF.2017.11.009

Chang, J. W., \& Wei, H.-Y. (2016). Exploring Engaging Gamification Mechanics in Massive Online Open Courses. Educational Technology \& Society, 19(2), 177-203. Retrieved from https://www.jstor.org/stable/jeductechsoci.19.2.177

Cheung, C. M. K., Shen, X.-L., Lee, Z. W. Y., \& Chan, T. K. H. (2015). Promoting sales of online games through customer engagement. Electronic Commerce Research and Applications, 14(4), 241-250. doi: 10.1016/j.elerap.2015.03.001

Decker, R., \& Trusov, M. (2010). Estimating aggregate consumer preferences from online product reviews. International Journal of Research in Marketing, 27(4), 293-307. doi: 10.1016/J.IJRESMAR.2010.09.001

Gatautis, R., Vitkauskaite, E., Gadeikiene, A., \& Piligrimiene, Z. (2016). Gamification as a Mean of Driving Online Consumer Behaviour: SOR Model Perspective. Engineering Economics, 27(1), 90-97. doi: 10.5755/j01.ee.27.1.13198

Hamari, J. (2017). Do badges increase user activity? A field experiment on the effects of gamification. Computers in Human Behavior, 71, 469-478. doi: 10.1016/j.chb.2015.03.036

Hamari, J., Alha, K., Järvelä, S., Kivikangas, J. M., Koivisto, J., \& Paavilainen, J. (2017). Why do players buy in-game content? An empirical study on concrete purchase motivations. Computers in Human Behavior, 68, 538-546. doi: 10.1016/j.chb.2016.11.045

Hamari, J., \& Koivisto, J. (2014). Measuring flow in gamification: Dispositional Flow Scale-2. Computers in Human Behavior, 40, 133-143. doi: 10.1016/J.CHB.2014.07.048

Hamari, J., \& Tuunanen, J. (2014). Player Types: A Meta-synthesis. Transactions of the Digital Games Research Association, 1(2), 29-53. doi: 10.26503/todigra.v1i2.13

Hammedi, W., Leclerq, T., \& Van Riel, A. C. R. (2017). The use of gamification mechanics to increase employee and user engagement in participative healthcare services. Journal of Service Management, 28(4), 640-661. doi: 10.1108/JOSM-04-2016-0116

Haziri, F., Chovancová, M., \& Fetahu, F. (2019). Game mechanics and aesthetics differences for tangible and intangible goods provided via social media. Management and Marketing - Challenges for the Knowledge Society, 14(2), 176-187. doi: 10.2478/mmcks-2019-0012

Haziri, F., \& Chovancova, M. (2018). Game mechanics differences for Kosovars social media purchasers. Paper presented at 36th International Scientific Conference on Economic and Social Development - "Building Resilient Society", Zagreb, Croatia. Zagreb: Varazdin Development and Entrepreneurship Agency. Retrieved from https://search.proquest.com/openview/ee797ad5b0b0c5e4475761796c9508a1/1?pqorigsite $=$ gscholar $\& \mathrm{cbl}=2033472$ 
Hsu, C.-L., \& Chen, M.-C. (2018). How gamification marketing activities motivate desirable consumer behaviors: Focusing on the role of brand love. Computers in Human Behavior, 88, 121-133. doi: 10.1016/J.CHB.2018.06.037

Institute of Statistics - Instat. (2019). Employment by administrative source and agricultural sector. Retrieved from http://www.instat.gov.al/en/themes/labour-market-andeducation/administrative-data-on-labour-market/\#tab1

Internet World Stats (2018). World Internet Users Statistics. Retrieved from https://www.internetworldstats.com/stats.htm

Kim, J. T., \& Lee, W.-H. (2015). Dynamical model for gamification of learning (DMGL). Multimedia Tools and Applications, 74(19), 8483-8493. doi: 10.1007/s11042-0131612-8

Kim, S., \& Park, H. (2013). Effects of various characteristics of social commerce (s-commerce) on consumers' trust and trust performance. International Journal of Information Management. doi: 10.1016/j.ijinfomgt.2012.11.006

Landers, R. N., Bauer, K. N., \& Callan, R. C. (2017). Gamification of task performance with leaderboards: A goal setting experiment. Computers in Human Behavior, 71, 508-515. doi: 10.1016/j.chb.2015.08.008

Lieberoth, A. (2015). Shallow Gamification: Testing Psychological Effects of Framing an Activity as a Game. Games and Culture, 10(3), 229-248. doi: $10.1177 / 1555412014559978$

Martin Poole, S., Kemp, E., Patterson, L., \& Williams, K. (2014). Get your head in the game: using gamification in business education to connect with generation Y. Journal for Excellence in Business Education, 3(2). Retrieved from http://www.jebejournal.org/index.php/jebe/article/view/40

McGuire, A., Broin, D. O., White, P. J., \& Deevy, C. (2018). The effect of game elements in a career awareness system. Paper presented at European Conference on Games Based Learning, Reading, UK. Reading: Academic Conferences International. Retrieved from https://search.proquest.com/openview/d752a033dcee385b5b73fb54970c060a/1?pqorigsite $=$ gscholar \&cbl $=396495$

Mekler, E. D., Brühlmann, F., Tuch, A. N., \& Opwis, K. (2017). Towards understanding the effects of individual gamification elements on intrinsic motivation and performance. Computers in Human Behavior, 71, 525-534. doi: 10.1016/j.chb.2015.08.048

Nour, M. M., Rouf, A. S., \& Allman-Farinelli, M. (2018). Exploring young adult perspectives on the use of gamification and social media in a smartphone platform for improving vegetable intake. Appetite, 120, 547-556. doi: 10.1016/j.appet.2017.10.016

Olbrich, R., \& Holsing, C. (2011). Social Commerce. WiSt - Wirtschaftswissenschaftliches Studium. doi: 10.15358/0340-1650-2011-6-314

Rahman, M. N. A., Jaafar, J., Kadir, M. F. A., Shamsuddin, S. N., \& Saany, S. I. A. (2018). Cloud Based Gamification Model Canvas for School Information Management. International Journal of Engineering \& Technology, 7(2.14), 28-31. doi: 10.14419/ijet.v7i2.14.11148

Scheiner, C. W. (2015). The Motivational Fabric of Gamified Idea Competitions: The Evaluation of Game Mechanics from a Longitudinal Perspective. Creativity and Innovation Management, 24(2), 341-352. doi: 10.1111/caim.12115 
Shin, D. H. (2013). User experience in social commerce: In friends we trust. Behaviour and Information Technology, 32(1), 52-67. doi: 10.1080/0144929X.2012.692167

Tabachnick, B. G., \& Fidell, L. S. (2014). Using multivariate statistics. Harlow: Pearson.

Werbach, K., \& Hunter, D. (2012). For the win: how game thinking can revolutionize your business. Wharton: Wharton Digital Press.

\section{Contact information}

\section{Fortesa Haziri}

Tomas Bata University in Zlín, Faculty of Management and Economics Mostní 5139, 76001, Zlín, Czech Republic

E-mail: haziri@utb.cz, fortesa.haziri@gmail.com

ORCID: 0000-0002-0804-3801

\section{Fortune Nwaiwu}

Tomas Bata University in Zlín, Faculty of Management and Economics Mostní 5139, 76001, Zlín, Czech Republic

E-mail: nwaiwu@utb.cz

ORCID: 0000-0001-8900-2130

doc. Ing. Miloslava Chovancová, CSc.

Tomas Bata University in Zlín, Faculty of Management and Economics Mostní 5139, 76001, Zlín, Czech Republic

E-mail: chovancova@utb.cz

ORCID: 0000-0002-9244-9563

doi: $10.7441 /$ dokbat.2019.032 